\title{
The Development of Chitosan-Maltodextrin Polymer Electrolyte with the Addition of Ionic Liquid for Electrochemical Double Layer Capacitor (EDLC) Application
}

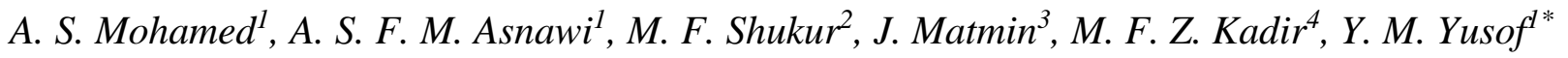 \\ ${ }^{1}$ Chemical Engineering Section, Universiti Kuala Lumpur, Malaysian Institute of Chemical \& \\ Bioengineering Technology (UniKL MICET), 78000 Alor Gajah, Malacca \\ ${ }^{2}$ Fundamental and Applied Sciences Department, Universiti Teknologi PETRONAS, 32610 Seri \\ Iskandar, Perak, Malaysia \\ ${ }^{3}$ Department of Chemical Science, University of Technology Malaysia, 81310 Johor Bahru, Johor, \\ Malaysia \\ ${ }^{4}$ Centre for Foundation Studies in Science, University of Malaya, 50603 Kuala Lumpur, Malaysia \\ *E-mail: yuhanees@unikl.edu.my
}

Received: 20 October 2021 / Accepted: 20 December 2021 / Published: 2 February 2022

In this paper, chitosan-maltodextrin based solid polymer electrolytes doped with ammonium chloride $\left(\mathrm{NH}_{4} \mathrm{Cl}\right)$ as proton provider and 1-butyl-3-methylimidazolium chloride (BMIM-Cl) as plasticizer are prepared through solution casting method. The conductivity of salted electrolyte is increased to (1.28 \pm $0.06) \times 10^{-3} \mathrm{~S} \mathrm{~cm}^{-1}$ with the inclusion of $50 \mathrm{wt}$.\% BMIM-Cl. The electrolytes are thermally assisted when the temperature is increased which obeys the Arrhenius rule. The complexation between polymers, salt, and plasticizer has been proven through the deconvolution of Fourier transference infrared (FTIR). The non-Debye behaviour is verified from the dielectric analysis. Deconvolution of X-ray diffraction (XRD) pattern presented the lowest degree of crystallinity for the highest ionic conducting electrolyte. The scanning electron microscope (SEM) and atomic force microscopy (AFM) analyses had been applied whereby the highest ionic conducting electrolyte exhibited a tunnel pattern on the surface which proved high amorphous characteristic. Transference number (TNM) analysis has confirmed that the ions are the dominant charge carriers in the electrolytes. Linear sweep voltammetry (LSV) and cyclic voltammetry (CV) analysis had been carried out prior to the fabrication of EDLC. The highest value of specific capacitance is found at $56 \mathrm{~F} \mathrm{~g}^{-1}$ where the range of energy density and power densities are between 2.5 to $9.0 \mathrm{Wh} \mathrm{kg}^{-1}$ and 137 to $276 \mathrm{~W} \mathrm{~kg}^{-1}$, respectively.

Keywords: Biopolymer electrolyte; chitosan-maltodextrin blend; ammonium chloride; ionic liquid; electrochemical double-layer capacitor

\section{FULL TEXT}


(C) 2022 The Authors. Published by ESG (www.electrochemsci.org). This article is an open access article distributed under the terms and conditions of the Creative Commons Attribution license (http://creativecommons.org/licenses/by/4.0/). 